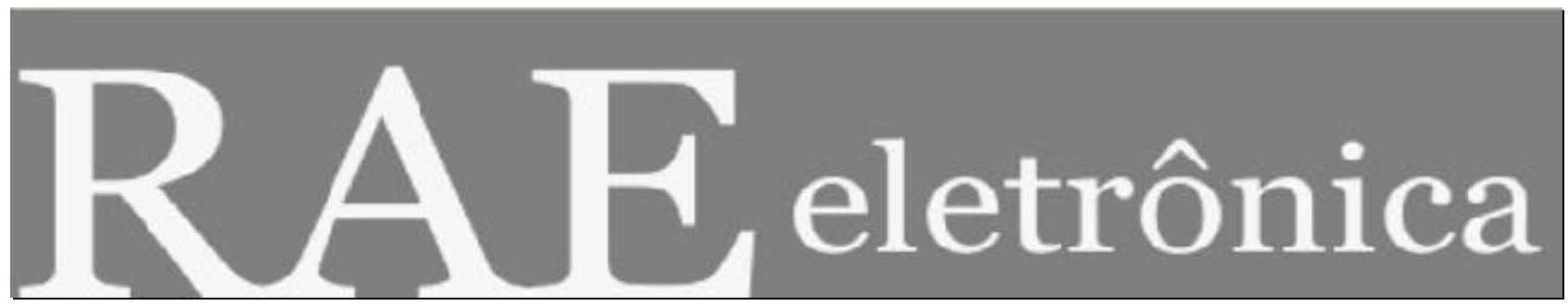

FÓRUM ESTUDOS CRÍTICOS EM ADMINISTRAÇÃO

\title{
RESPONSABILIDADE SOCIAL CORPORATIVA: POR UMA BOA CAUSA!?
}

Por:

\section{Gianna Maria de Paula Soares}

RAE-eletrônica, v. 3, n. 2, Art. 23, jul./dez. 2004

http://www.rae.com.br/eletronica/index.cfm?FuseAction=Artigo \&ID=1666\&Secao=FOR.ESTCRI\&V olume $=3 \&$ Numero $=2 \& A n o=2004$

CCopyright, 2004, RAE-eletrônica. Todos os direitos, inclusive de tradução, são reservados. É permitido citar parte de artigos sem autorização prévia desde que seja identificada a fonte. A reprodução total de artigos é proibida. Os artigos só devem ser usados para uso pessoal e nãocomercial. Em caso de dúvidas, consulte a redação: redacao@ rae.com.br.

A RAE-eletrônica é a revista on-line da FGV-EAESP, totalmente aberta e criada com o objetivo de agilizar a veiculação de trabalhos inéditos. Lançada em janeiro de 2002, com perfil acadêmico, é dedicada a professores, pesquisadores e estudantes. Para mais informações consulte o site www.rae.com.br/eletronica.

\section{RAE-eletrônica}

ISSN 1676-5648

(C2004 Fundação Getulio Vargas - Escola de Administração de Empresas de São Paulo.

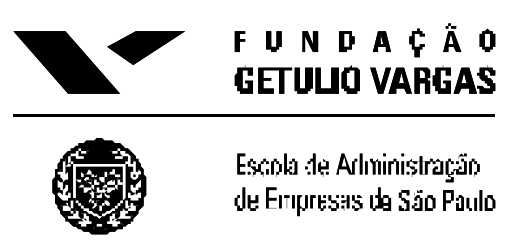




\section{RESPONSABILIDADE SOCIAL CORPORATIVA: POR UMA BOA CAUSA!?}

\section{RESUMO}

A responsabilidade social corporativa é um tema que vem atraindo a atenção da sociedade. Neste movimento, as organizações se propõem a assumir uma postura socialmente responsável em relação às injustiças sociais e à degradação da natureza. Por outro lado, estudos apontam no sentido de que a leitura atenta dos discursos organizacionais revela palavras sequer pronunciadas e de que existem contradições entre o que os membros das organizações assumem como sendo ética, moral e democracia e o que efetivamente é praticado no ambiente organizacional. Partindo desses estudos, o presente ensaio pretende revelar a outra face da responsabilidade social corporativa. Desta forma, três tipos de discurso são identificados, quais sejam, o explicitado, o pronunciado reservadamente e o não-dito. Uma análise crítica do discurso não-dito revela o que se esconde por trás das ações preconizadas pela responsabilidade social corporativa bem como as contradições inerentes a essas práticas.

\section{ABSTRACT}

The new corporate social responsibility movement is attracting society's attention. In this movement, the corporative controllers would be facing the current conditions of social injustices and degradation of the envirement. On the other hand, studies show that a careful reading of the organizational speeches discloses words not even uttered and that there are contradictions between what the members of the organizations assume as being ethical, moral and democracy and what effectively is practised in the organizational environment. This essay was oriented by theses studies and the research allows some comments. Three types of speech could have been identified, which are, the public, the private and the one that is not declared. A critical analyses of the not declared speech disclosed what it is hidden for backwards of the actions praised by the corporative social responsibility as well as the inherent contradictions to this movement.

\section{PALAVRAS-CHAVE}

Responsabilidade social corporativa; discursos; contradições; capitalismo;

\section{KEY-WORDS}

Corporate social responsibility; speeches; contradictions; capitalism; 


\section{INTRODUÇÃO}

Gianna Maria de Paula Soares

A responsabilidade social corporativa tornou-se um tema recorrente no âmbito das organizações ao longo da última década. Esse movimento se caracteriza fundamentalmente por uma proposta de retomada das questões éticas tanto no âmbito interno das organizações como no seu relacionamento com o público externo, qual seja, consumidores, clientes, fornecedores, Governo e acionistas, os chamados stakeholders.

As organizações, a partir de uma postura dita socialmente responsável, vêm empreendendo ações sociais que vão desde a tradicional filantropia até parcerias com o terceiro setor, e incluem programas de voluntariado empresarial e de proteção ao meio-ambiente, além da instituição de códigos de ética que visam regulamentar a conduta de seus membros .

Constata-se, entretanto, que, ainda que importantes contribuições a uma visão crítica a respeito da responsabilidade social corporativa devam ser assinaladas (FREITAS, 2000; PAULA; PINTO; PAIVA, 2001; CORREIA; MEDEIROS, 2002; FABIÃO, 2002), grande parte dos estudos que abordam o assunto se caracterizam por uma visão bastante otimista em relação ao tema.

Tem-se observado, todavia, que por trás do discurso cobertura, que deixa transparecer apenas as boas intenções e as motivações socialmente admissíveis para esse novo paradigma organizacional, existem outras razões que levam as organizações a aderirem ao movimento pelo social, razões essas que nem sempre são assumidas publicamente e, em sua maioria, não são questionadas pelo mundo acadêmico. Pode-se, ainda, apontar para contradições existentes entre o que as organizações pregam sobre as ações ditas sociais e as práticas organizacionais. Além disto, e principalmente, deve-se questionar as condições reais de se eliminar as contradições sociais no âmbito de um sistema que se caracteriza, ele próprio, como uma contradição viva, como é o capitalismo (MÉSZÁROS, 2002; 2003).

Assim, pretende-se neste ensaio teórico lançar um olhar crítico sobre o fenômeno da responsabilidade social corporativa, de forma a revelar algumas contradições entre esse movimento e o sistema do capital, no qual estão inseridas as organizações, bem como fazer vir à tona o que os discursos organizacionais vêm se esforçando em ocultar.

É preciso, primeiramente, esclarecer que o presente artigo se propõe a discutir não as ações sociais em seu caráter individual, mas sim a totalidade das ações que se encontram sob o leque da responsabilidade social corporativa, de forma que se possa identificar as contradições e as outras motivações envolvidas no movimento da responsabilidade social corporativa, e questionar a capacidade e o interesse efetivos das organizações em resolverem as adversidades sociais e ambientais.

Considerando-se que a responsabilidade social corporativa se assenta sobre três pilares fundamentais, quais sejam, a ética empresarial, a preservação dos recursos naturais e o respeito aos trabalhadores, inicia-se o presente trabalho com uma discussão sobre as relações que se estabelecem entre o capital e os três elementos fundamentais das ações socialmente responsáveis, permitindo analisar as contradições inerentes ao próprio capitalismo. Em seguida, a partir de uma leitura atenta dos discursos que sustentam as ações de responsabilidade social, procura-se investigar as razões que estão ocultas por trás da benevolência do capital para com o social, bem como expor contradições entre o que se prega e o que efetivamente se pratica no âmbito das organizações; a discussão encerra-se com a conclusão do trabalho. 


\title{
O CAPITAL E A ÉTICA, OS RECURSOS NATURAIS E OS "RECURSOS" HUMANOS
}

Os indivíduos reproduzem sua existência por meio de funções primárias de mediações que se estabelecem entre eles e no intercâmbio e interação com a natureza, dadas "pela ontologia singularmente humana do trabalho" (ANTUNES, 2002, p. 20). A funcionalidade das mediações de primeira ordem, entretanto, foi afetada pelo advento das mediações de segunda ordem do capital, que passou a conduzir as primeiras, em uma inversão da lógica societal, cuja efetivação instituiu o sistema de metabolismo social do capital.

Nesse sistema, o capital ${ }^{2}$, desprovido de uma orientação humanamente significativa, assume uma lógica na qual o valor de uso é totalmente subordinado ao valor de troca (ANTUNES, 2002), caracterizando-se, deste modo, como um sistema sem limites para sua expansão e que é movido pela acumulação. Pode-se afirmar, portanto, que o sistema de capital, que se articula em uma rede de contradições que, invariavelmente, têm raízes no antagonismo entre capital e trabalho (MÉSZÁROS, 2003), é ontologicamente incontrolável (ANTUNES, 2002) e, devido a sua lógica de reprodução incessante, assume uma configuração crescentemente destrutiva.

Dentro desse contexto, percebe-se que a produção, que em sua essência deveria estar voltada para o atendimento das necessidades humanas, tem por fundamento as necessidades de auto-reprodução do capital; isto engendra uma situação na qual:

\begin{abstract}
quanto mais aumentam a competição e a concorrência inter-capitais, mais nefastas são as suas conseqüências, das quais duas são particularmente graves: a degradação e/ou precarização, sem paralelos em toda a era moderna, da força humana que trabalha e a degradação crescente do meio-ambiente, na relação metabólica entre homem, tecnologia e natureza, conduzida pela lógica societal subordinada aos parâmetros do capital e do sistema reprodutor de mercadorias. (ANTUNES, 2002, p. 26).
\end{abstract}

Assim sendo, não aderindo a um "exagerado otimismo cheio de explicações que separa os efeitos de suas causas" (MÉSZÁROS, 2002, p. 39), pode-se constatar que é a própria estrutura do sistema do capital, em sua lógica de reprodução incessante, que redunda nas condições atuais de desigualdades sociais e deterioração da natureza, condições essas, que as organizações, através de ações de responsabilidade social corporativa, pretendem combater.

Pretende-se, portanto, a partir do exame das relações que se estabelecem entre o capital e a ética, os recursos naturais e o trabalho, demonstrar que a incapacidade das organizações de construir um mundo melhor por meio do movimento da responsabilidade social é congênita, visto que os principais problemas que essas ações se propõem a solucionar são parte das contradições inerentes ao próprio sistema do capital.

\section{A ética no capitalismo}

No presente trabalho, a ética é entendida como se referindo ao comportamento autônomo do indivíduo capaz de desejo (CHAUI, 1994, citado por FARIA, 2000), de forma que se julga que "a ética avalia então os costumes, aceita-os ou reprova-os" (SROUR, 1998, p.271); a moral, por sua vez, é tomada 


\title{
FÓRUM ESTUDOS CRÍTICOS EM ADMINISTRAÇÃO- RESPONSABILIDADE SOCIAL \\ CORPORATIVA: POR UMA BOA CAUSA? \\ Gianna Maria de Paula Soares
}

como referente ao comportamento normativo, em que as regras são definidas pela sociedade (CHAUI, 1994, citado por FARIA, 2000).

Considerando-se que o que predomina no sistema capitalista é a lógica da acumulação, constata-se que na sociedade contemporânea os valores intrínsecos ao capitalismo, como competição e lucro, se sobrepõem aos valores políticos e aos que dizem respeito à vida psíquica dos indivíduos. Assim sendo, o que se institui no capitalismo é a presença de ideologias pseudo-éticas, que ditam as regras das condutas, de forma que, como afirmam Faria e Meneghetti (2001 b, p. 3), se pode crer que

\begin{abstract}
a moral e a ética parecem também sofrer alterações em função de uma nova redefinição econômica, social e ideológica, no interior de um 'espírito capitalista [que está presente] em todas as instâncias da sociedade, seja nas formas de subjetividade psíquica de ideologia dominante, de valores individualistas, de apontamento possessivo, de mercantilização ou de terceirização do afeto.
\end{abstract}

Deste modo, em nome da guerra econômica que impera na atualidade, "admite-se atropelar certos princípios, [pois] o fim justificaria os meios" (DEJOURS, 2001, p. 14). Esses fins, entretanto, são sempre definidos em termos econômicos, a partir de um cálculo custo-benefício que despreza as variáveis humanas e sociais. Porém, conforme afirma Chauí (1992, pp. 354-355), em se tratando de ética, "os meios precisam estar de acordo com a natureza dos fins e, portanto, para fins éticos os meios precisam ser éticos também, (...) uma vez que as ações realizadas em vista de um certo fim já fazem parte do próprio fim a ser atingido." Assim, questiona-se a autora se

\footnotetext{
em uma sociedade [como a capitalista] que afirma o valor da competição e da vitória sobre os outros como prova de superioridade e, portanto, transforma a competição e a vitória em valores morais, poderia tal sociedade afirmar que houve separação entre meios e fins quando, para alcançar a vitória, todos os meios competitivos são considerados bons (seforem eficazes)?
}

Logo, pode-se afirmar que "os imperativos da competição, deificada como arranjo intransponível das relações de produção da vida material, transforma a violência em modelo de ação humana destruindo as possibilidades éticas [no âmbito do capitalismo]" (FARIA, 2000, p. 8).

\section{Os recursos naturais no capitalismo}

O trabalho, enquanto valor de uso, é o ato de depositar significado humano à natureza, de forma que sempre será o metabolismo entre o homem e a natureza (CODO et al., 1994). Nas palavras de Marx (1985, p. 149), "antes de tudo, o trabalho é um processo entre o homem e a natureza, um processo em que o homem, por sua própria ação, media, regula e controla seu metabolismo com a Natureza. Ele mesmo se defronta com a matéria natural como uma força natural."

O advento das mediações de segunda ordem, contudo, se sobrepôs à atividade produtiva essencial dos indivíduos sociais e à mediação primária existente entre eles, subordinando a natureza aos imperativos de reprodução do capital, acarretando uma situação em que ambos, homem e natureza, perdem a identidade, tornando-se estranhos um ao outro (KRAHL, 2002).

Constata-se, então, que a lógica societal voltada prioritariamente para a produção de mercadorias e para o processo de valorização do capital engendra um movimento contraditório entre o crescimento da produção a qualquer custo e a concomitante destruição ambiental (MÉSZÁROS, 2003), pois uma 


\begin{abstract}
FÓRUM ESTUDOS CRÍTICOS EM ADMINISTRAÇÃO - RESPONSABILIDADE SOCIAL
CORPORATIVA: POR UMA BOA CAUSA?

Gianna Maria de Paula Soares

contradição básica do sistema capitalista de controle é que este não pode separar 'avanço' de destruição, nem 'progresso' de desperdício - ainda que as resultantes sejam catastróficas. (...) [Isto] causa um duplo malefício (...) por usar com desperdício voraz os limitados recursos do nosso planeta, o que é posteriormente agravado pela poluição e pelo envenenamento do meio ambiente humano, decorrentes da produção em massa de lixo e efluentes. (MÉSZÁROS, 2002, p. 1010).
\end{abstract}

Com efeito, como afirma Stahel (2001), a crise ecológica é apenas o reflexo do caráter insustentável e contraditório do próprio capitalismo. Is to permite compreender que

\begin{abstract}
o incontestável imperativo da proteção ambiental se revelou inadministrável em virtude das correspondentes restrições necessárias aos processos de produção em vigor exigidas para sua implementação, (...) [visto que] qualquer tentativa de tratar dos problemas relutantemente admitidos deve ser empreendida sob o peso proibitivo de leis fundamentais e antagonismos estruturais do sistema. Assim, as 'medidas corretivas' contempladas em grandes encontros festivos (...) acabam em malogro, pois estão subordinadas à perpetuação de relações de poder e interesses globais estabelecidos. (MÉSZÁROS, 2002, pp. 95, 223).
\end{abstract}

Conseqüentemente, pode-se concluir com Mészáros (2002, p. 253) que "a degradação da natureza (...) não tem qualquer significado para o seu [do capital] sistema de controle sociometabólico, em relação ao imperativo absoluto de sua auto-reprodução numa escala cada vez maior."

\title{
Os "Recursos" humanos e o capital
}

O que distingue o homem e permite ao ser humano tornar-se efetivamente humano é a produção de sua própria existência; o trabalho, portanto, consiste de uma dupla transformação de si e do mundo, e engendra o homem como ser de necessidades e imaginação, capaz de construir sua sociabilidade e suas condições de existência. Estabelece-se, desta forma, entre o homem e a natureza, uma relação dialética, pois "ao atuar (...) sobre a Natureza externa a ele e ao modificá-la, ele modifica, ao mesmo tempo, a sua própria natureza. Ele desenvolve as potências nele adormecidas e sujeita o jogo de forças a seu próprio domínio.” (MARX, 1985, p. 149).

Entretanto, como a força de trabalho é o único valor de uso capaz de criar valor (CODO et al, 1994), a apropriação do trabalho excedente da sociedade tornou-se condição vital para a reprodução incessante do capital e resultou no antagonismo estrutural e inconciliável entre capital e trabalho. Porém, "o homem se transforma ao transformar, pelo domínio, a natureza, constrói a si mesmo: quando vende seu trabalho, vende a transformação que a natureza opera em si, sua hominização que, por sua vez, enquanto mercadoria, lhe aparece como objeto independente, vendido ao empregador em troca de salário." (CODO , 1994, p. 146)

Assim, a relação de compra e venda de força de trabalho, que caracteriza o capitalismo, implica em que a própria força de trabalho seja tratada como mercadoria (CHESNAIS, 1996; MÉSZÁROS, 2002), redundando em uma situação na qual as relações de trabalho, em seus vários níveis de concretização, são, de fato, relações de poder (BRAVERMAN, 1977; CODO et al., 1994; FARIA, 1997).

Nesse contexto, o trabalho é excluído de todas as decisões significativas, 


\section{FÓRUM ESTUDOS CRÍTICOS EM ADMINISTRAÇÃO-RESPONSABILIDADE SOCIAL \\ CORPORATIVA: POR UMA BOA CAUSA? \\ Gianna Maria de Paula Soares}

pois o capital (...) não pode funcionar sem tornar suas decisões absolutamente inquestionáveis (pela força de trabalho), (...) é por isto que o modo de tomada de decisão do capital - em todas as variedades conhecidas ou viáveis do sistema do capital - há de ser forçosamente alguma forma autoritária de administrar empresas do topo para base (MÉSZÁROS, 2002, p. 27).

Na dinâmica das relações de trabalho, que reflete a relação dialética que se estabelece entre capitaltrabalho-Estado, o movimento do capital no sentido de manter a sua dominação se faz acompanhar de um movimento de resistência da classe trabalhadora tanto dentro das fábricas como fora delas, em sindicatos e partidos. Assim, como sugere Enriquez (1995, p.13), "ele [o capital] teve que transformarse, renovar seus métodos, tornar-se mais inventivo e assegurar aos trabalhadores um melhor retorno e condições de trabalho decentes." Entretanto, as alterações no mundo do trabalho, marcadas pela mecanização e robotização, que transformaram trabalhadores "braçais 'cheirando a suor' em operários de mãos limpas" (DEJOURS, 2001, p. 27), não atenuaram o sofrimento dos que trabalham, pois inúmeras atividades ainda apresentam riscos à vida e à saúde do trabalhador, e muitas são as fontes de sofrimento psíquico.

Aos efeitos perversos do capitalismo sobre o trabalhador, some-se o crescente desemprego estrutural, decorrente das contradições e antagonismos do sistema do capital, a precarização da força de trabalho, nas formas de terceirização, de subempregos, de trabalho assalariado da economia informal, além da intensificação do ritmo de trabalho, imposta pela tecnologia de base microeletrônica.

Constata-se, consequientemente, que o capitalismo "não devia interessar-se pelo indivíduo senão sob duas modalidades: enquanto indivíduo competitivo (...) ou enquanto pessoa manipulável e sujeito a trabalho forçado." (ENRIQUEZ ,1995, p.10).

\section{O CAPITAL E A RESPONSABILIDADE SOCIAL CORPORATIVA}

Desde o inicio dos anos 70, o capital vem experimentando uma crise estrutural, que segundo Mészáros (2003), se distingue das crises anteriores por ser uma fase stop de duração excepcionalmente longa e por demonstrar características de uma crise mais ou menos permanente e crônica, com a perspectiva de uma profunda crise estrutural que tem origem na lógica destrutiva e na incontrolabilidade do sistema sociometabólico do capital.

Neste contexto, a responsabilidade social corporativa pode ser entendida como uma dupla resposta à atual crise vivenciada pelo capital. A primeira delas, nos termos da dominação da empresa na sociedade atual, que, como se examinará mais adiante, busca se tornar a instituição das instituições. A outra, no sentido que a mudança nos padrões da concorrência, decorrente da crise econômica, obriga as organizações a adaptarem seu processo de trabalho às novas exigências do mercado globalizado e a adequarem sua estrutura aos padrões de parceiros internacionais ou aos requisitos decorrentes de processos de fusão e incorporação.

De acordo com Srour (1998, p. 293), o que direciona as empresas para o lucro com responsabilidade, em detrimento da pura maximização do lucro, é o fato de que, como "as relações que amarram empresa e contrapartes são relações de poder", os stakeholders podem se mobilizar e retaliar a empresa que desrespeite normas básicas do trato com a sociedade. 


\title{
FÓRUM ESTUDOS CRÍTICOS EM ADMINISTRAÇ̃̃O- RESPONSABILIDADE SOCIAL \\ CORPORATIVA: POR UMA BOA CAUSA? \\ Gianna Maria de Paula Soares
}

Por outro lado, Enriquez (1997b) defende que esse movimento não passaria de uma forma de se manter à altura das expectativas do mercado ao mesmo tempo em que se perpetuam as relações de poder, de modo que denomina a "nova" ética demonstrada pelas empresas de ética travestida.

\section{OS DIVERSOS DISCURSOS}

As organizações envolvidas em ações de responsabilidade social, como empresas, entidades sem fins lucrativos e empresas de consultoria costumam divulgar informações em sites da internet e em boletins específicos; a mídia, por sua vez, mantém a sociedade a par de acontecimentos que dizem respeito ao assunto. Além disto, muitos trabalhos acadêmicos têm sido apresentados em congressos e publicados em periódicos especializados, e livros têm sido editados sobre o tema.

Uma leitura atenta desse material permite se distinguir três tipos de discursos proferidos, quais sejam, o discurso explicitado, através do qual são divulgadas as informações a respeito da responsabilidade social que se pretende que sejam do conhecimento dos trabalhadores e do grande público, normalmente composto da massa de consumidores das empresas patrocinadoras das ações sociais; o discurso pronunciado reservadamente, que contempla as informações que, embora públicas, não são divulgadas no âmbito da população em geral e se encontra preponderantemente em trabalhos acadêmicos e livros especializados; e o discurso não-dito, revelado a partir de uma análise crítica dos discursos explicitado e pronunciado reservadamente.

\section{O discurso explicitado}

A responsabilidade social corporativa é entendida, de acordo com esse discurso, como:

\begin{abstract}
uma forma de conduzir os negócios da empresa de tal maneira que a torna parceira e coresponsável pelo desenvolvimento social. A empresa socialmente responsável é aquela que possui a capacidade de ouvir os interesses das diferentes partes (acionistas, funcionários, prestadores de serviço, fornecedores, consumidores, comunidade, governo e meio-ambiente) e conseguir incorporá-los no planejamento de suas atividades, buscando atender às demandas de todos e não apenas dos acionistas ou proprietários (Instituto Ethos, 2002).
\end{abstract}

Ao nível do discurso explicitado, assumir uma postura socialmente responsável significa, portanto, a empresa não se restringir a sua função econômica, passando a orientar-se pela função ética da responsabilidade social corporativa. Deste modo, em uma empresa socialmente responsável, o mecanismo de apropriação dos excedentes econômicos não beneficia de maneira exclusiva acionistas e proprietários, mas se estende aos demais stakeholders (SROUR, 1998).

Esse discurso, entretanto, não esconde que a mudança na postura da sociedade, que passa a exigir uma postura ética nas organizações, tenha sido, ao menos parcialmente, responsável pela "transformação" ocorrida (SROUR, 1998). Faz, porém, parecer que a organização está atendendo aos apelos da sociedade e tomando conta dela, escondendo, assim, o real sentido dessa (aparente) mudança. 


\section{FÓRUM ESTUDOS CRÍTICOS EM ADMINISTRAÇÃO-RESPONSABILIDADE SOCIAL \\ CORPORATIVA: POR UMA BOA CAUSA? \\ Gianna Maria de Paula Soares}

\section{O discurso pronunciado reservadamente}

O discurso pronunciado reservadamente aborda aspectos da responsabilidade social corporativa como estratégias de implementação da responsabilidade social com vistas a ampliar a oferta dos produtos da empresa no mercado, discussões sobre a conveniência ou não da empresa adotar ações sociais, tipos de ação social mais adequada à empresa e a quem a ação social deve se dirigir, em função do ramo de atuação empresarial (ASHLEY; MACEDO-SOARES, 2001).

No âmbito desse discurso, porém, se revela que o direcionamento das organizações para uma nova postura em relação ao social se deve à competitividade típica do regime capitalista, que vem sendo reforçada recentemente pelo fenômeno da globalização. Nesse contexto, a sobrevivência da empresa depende da vantagem comparativa que ela consiga obter em relação a seus concorrentes, para o que, a legitimidade, a boa imagem corporativa e a maior visibilidade no mercado decorrentes da adoção de programas de responsabilidade social corporativa são essenciais (SROUR, 1998).

Nesse sentido, pode-se afirmar que um posicionamento socialmente responsável por parte da organização representa uma estratégia de marketing, pois garante um diferencial competitivo, que se dá especialmente a partir da consolidação de uma imagem corporativa favorável não apenas junto aos clientes, que tendem a se tornar mais fiéis à marca do produto comercializado pela empresa, como também junto aos trabalhadores, pois reforça o comprometimento e identificação com a organização, tornando-se, desta maneira, mais produtivos.(GARAY, 2001).

Uma das modalidades de ação social que vem sendo crescentemente incentivada no âmbito da responsabilidade social corporativa é o voluntariado empresarial. $\mathrm{O}$ discurso pronunciado reservadamente apresenta o voluntariado como uma forma do trabalhador exercer a cidadania e cumprir seu papel frente à necessária transformação das realidades sociais. Por outro lado, ele afirma que os benefícios do trabalho voluntário remetem à questão da competitividade e da diferenciação necessária à sobrevivência das organizações, pois elevam o nível de satisfação e de identidade dos trabalhadores com a empresa, redundando em maior envolvimento com o trabalho, aumento do comprometimento organizacional, em desenvolvimento de competências, fortalecimento da cultura corporativa e consolidação de uma imagem corporativa favorável (GARAY, 2001).

Mencione-se ainda que, reservadamente, os programas de voluntariado empresarial têm sido considerados uma ferramenta de recursos humanos, o que por si só já descaracteriza o trabalho como social e voluntário, a não que se inverta a lógica e se considere como objeto do projeto social a empresa, e como o voluntário efetivamente o trabalhador.

\section{O não-dito}

"Todo discurso esconde uma rede simbólica de dominação ideológica e de poder" (FARIA; MENEGHETTI, 2001 a), de forma que a leitura dos discursos explicitado e pronunciado reservadamente, realizada ao amparo de um referencial teórico crítico, permite trazer a tona o "outro sentido" (ENRIQUEZ, 1974) da responsabilidade social corporativa, revelando um discurso cobertura que tem por objetivo transformar o interesse particular da organização em uma razão coletivamente aceita conferindo legitimidade ao que não é necessariamente legítimo (FARIA, 2000). Percorrendo as 


\section{FÓRUM ESTUDOS CRÍTICOS EM ADMINISTRAÇÃO-RESPONSABILIDADE SOCIAL \\ CORPORATIVA: POR UMA BOA CAUSA? \\ Gianna Maria de Paula Soares}

transformações do capitalismo ao longo dos séculos 19 e 20, Enriquez (1995) assinala a passagem de um capitalismo onde a empresa cumpria um papel central, mas não dominante, a um capitalismo onde a empresa busca se tornar a instituição das instituições. Nesse movimento, para responder às novas exigências formuladas pela sociedade, a empresa se traveste de uma determinada ética e, como um novo sagrado, passa a agir no sentido de suprir as deficiências das outras instituições; torna-se, então, a empresa cidadã, que conduz ações que favorecem a inscrição dos indivíduos no interior do corpo social (ENRIQUEZ, 1997 a; FREITAS, 2000). "Ela [a empresa] se encarrega não somente do desenvolvimento econômico da nação, mas também de seu desenvolvimento psicológico e cívico. (...) ela se considera com 'responsabilidade ilimitada" (ENRIQUEZ, 1997b, p. 10). Constata-se, portanto, que o desejo das empresas de se tornar a instituição por excelência da sociedade consiste de uma das instâncias do discurso não - dito.

Esse processo de ideologização conduzido pela empresa fez dela a portadora dos valores do capitalismo racional e instrumental, e transformou os seres humanos em seres técnicos e os homens, unicamente em produtores e consumidores. Entretanto, percebendo que o efeito da extrema competitividade, representada por uma multidão de cínicos, sabotadores e corruptos habitando o mundo organizacional, seria auto-destrutivo, a empresa engendra esforços no sentido de se colocar ela mesma como objeto dos afetos e das paixões, tornando-se, então, o lugar da socialização e do amor comunitário (ENRIQUEZ, 1997 b; FREITAS, 2000). O que a leitura do discurso não-dito revela, portanto, é que a postura de "empresa ética e guardiã da moral" (FREITAS, 2000) é a forma de se manter um mínimo de confiabilidade interna para que a empresa possa operar, dar lucros, crescer e se expandir, sobreviver, enfim.

Pode-se, ainda, dentro de uma perspectiva critica, examinar a proposta de voluntariado empresarial. A análise desses programas remete a inúmeros estudos (PAGÈS et al. 1987; CODO et al., 1994; DEJOURS, 2001; ENRIQUEZ, 2001; FARIA; MENEGHETTI, 2001c; LEAL; SCHMIDT, 2002) que demonstram que, no intuito de anular as práticas de questionamento das relações de dominação e poder presentes na organização e propiciar um controle mais amplo sobre o trabalhador, as organizações vêm desenvolvendo mecanismos de controle psicológico que atuam mediante o seqüestro da subjetividade do trabalhador.

\section{AS CONTRADIÇÕES}

O discurso explicitado prega que a adoção de programas de responsabilidade social corporativa implica em atitudes éticas com relação ao meio-ambiente, ao trabalhador e aos demais stakeholders da empresa. Pode-se, contudo, assinalar diversas contradições entre o que é assumido como sendo uma postura ética e o que é efetivamente praticado no mundo organizacional, no qual predomina, ainda que muito queiram negar, o interesse do capital sobre todos os outros.

Estudos (FARIA, 2000) revelam que há, nas organizações, um discurso sobre "uma certa ética e uma ação que não lhe corresponde" (FARIA; MENEGHETTI, 2001b, p.1), de forma que se pode questionar em que medida as ações propostas pela responsabilidade social corporativa correspondem à prática organizacional.

No âmbito da responsabilidade social corporativa, uma postura ética e responsável frente ao trabalhador deve contemplar a implementação da gestão participativa e de participação nos resultados 
da empresa e bonificação, programas de valorização da diversidade, compromisso com o desenvolvimento profissional e empregabilidade, cuidados com saúde, segurança e condições de trabalho e preparação para aposentadoria (Instituto Ethos, 2002).

Apesar do desempre go ser considerado a principal fonte de injustiça e de sofrimento na sociedade contemporânea, "o grande palco do sofrimento é certamente o do trabalho, tanto para os que dele se acham excluídos quanto para os que nele permanecem." como sustenta Dejours (2001, p. 37). O discurso corrente prega que, graças ao progresso da técnica, o mundo se livrou das misérias da condição operária; de fato, as tecnologias informacionais de base microeletrônica implicaram em redução dos índices de acidentes no trabalho e melhoria da qualidade do ambiente físico, e eliminaram diversas formas poluidoras do ambiente organizacional. Por outro lado, o que se verifica é que elas exigem a adoção de novas tecnologias de gestão, que consistem de formas mais sutis e efetivas de controle sobre os trabalhadores (FARIA, 1997, 2002; FARIA; MENEGUETTI, 2001c). A gestão participativa, por exemplo, como afirma Faria (1997, p. 98), "não é senão uma nova forma de dominação e de compromisso, pois os funcionários continuam subjugados ao poder do capital".

Dentro desse contexto, constata-se que por trás das vitrinas do progresso há um mundo de sofrimento nos bastidores do trabalho. Dentre as formas típicas de sofrimento que afetam o trabalhador moderno, mencione-se o medo da incompetência, a falta de esperança de reconhecimento, o medo do desemprego, quando não o próprio desemprego, a pressão por altos índices de produtividade e o rígido controle gerencial (DEJOURS, 2001).

Acrescente-se a isso, o fato de que as concessões do capital ao trabalho, obtidas às custas das grandes lutas sociais, têm se mostrado reversíveis (MÉSZÁROS, 2002), na medida em que até mesmo as legislações em torno do trabalho assalariado "voaram pelos ares" (CHESNAIS, 1996).

Além disso, mencione-se que estudos apontam na direção de um mundo do trabalho em que o assédio moral e o sexual estão presentes (FREITAS, 2001); em que as normas e regras, que ainda ocupam lugar central na vida organizacional, se constituem de formas de regulamentar as relações e as emoções, através da instrumentalização das pessoas e da negação de sua subjetividade (LÉVY, 2001); e em que a violência permanece institucionalizada (FARIA; MENEGUETTI, 2002).

Constata-se ainda que a lógica econômica, que prepondera no ambiente organizacional e que é representada pela ideologia do realismo econômico, faz o cinismo passar por força de caráter, por determinação e por um elevado senso de responsabilidades coletivas, em um cenário em que as vítimas da guerra econômica são inevitáveis e em que todos são convocados a integrarem o sistema de "banalização das injustiças sociais" (DEJOURS, 2001).

Verifica-se, portanto, que a distância entre o mundo do trabalho presumido pela proposta de responsabilidade social corporativa e o que é revelado pelos estudos acima é grande. Inúmeros fatores que operam no quotidiano do trabalho e que engendram uma realidade organizacional permeada de situações conflituosas e contraditórias não são contemplados sequer indiretamente no âmbito da proposta da responsabilidade social corporativa. Isto denota que, de fato,

o ideólogo organizacional deseja construir princípios da moral, do direito, da ética, da democracia e do comportamento que devem ser respeitados na organização, não baseado na realidade das condições sociais que lhe dão suporte, mas partindo de um conceito já previamente formulado no interior de seu grupo, sua seita ou corporação, sobre o que é moral, direito, ética, democracia e comportamento. (...) Neste sentido, o conceito de princípio ético, 


\section{FÓRUM ESTUDOS CRÍTICOS EM ADMINISTRAÇÃO-RESPONSABILIDADE SOCIAL \\ CORPORATIVA: POR UMA BOA CAUSA? \\ Gianna Maria de Paula Soares}

moral e democrático pode ser o que for mais conveniente aos seus elaboradores e usuários ocasionais.(FARIA, 2000, p. 13).

Pode-se argumentar que à empresa socialmente responsável é recomendado que adote um código de ética, de forma a regulamentar o comportamento de seus membros e introduzir uma "nova ética" no ambiente organizacional. Examinando-se, entretanto, os aspectos a serem contemplados no citado código $^{3}$, constata-se que esses se limitam a regulamentar as perspectivas teóricas sobre ética, moral e democracia apontadas em pesquisa realizada com gestores organizacionais (FARIA,2000). Fica, deste modo, evidente que os paradoxos do autoritarismo e preconceito, da injustiça e da autopreservação, da subordinação ética e competitividade, do conformismo, da desvalorização humana e da autodepreciação, apontados na citada pesquisa, tendem a se manter, permitindo concluir, portanto, que a mera implementação da responsabilidade social corporativa não operacionalizará nenhuma transformação na realidade organizacional.

\section{CONCLUSÃO}

As condições atuais de vida no planeta são resultado da lógica de reprodução incessante do capital. Desta forma, o processo de recomposição da unidade entre o homem e a natureza deve passar pela compreensão de que as questões ambientais não se originam exclusivamente das relações entre o homem e a natureza; assim, a introdução de um novo sistema produtivo, que inclua uma transformação integral da estrutura social, é condição básica para a solução dos problemas ambientais.

Além disso, não há o que se falar em nova postura ética perante o trabalhador enquanto perdurarem a compra de força de trabalho e a detenção dos meios de produção pelo capital, pois, como afirma Marx (1985, p. 140), "a natureza não produz de um lado possuidores de dinheiro e de mercadorias e, do outro, meros possuidores das próprias forças de trabalho".

No que se refere às injustiças sociais, tendo em vista o poderoso efeito multiplicador do sofrimento no trabalho sobre elas apontado por Dejours (2001), entende-se que quem quer que se preocupe com qualquer uma das inúmeras maneiras como as injustiças se manifestam na sociedade, deve se ater ao tema do sofrimento no trabalho, procurando compreender seu mecanismo de ação e formas de convertê-lo, como sugere o autor, em sofrimento criativo.

Este trabalho procurou, como uma maneira de se ir além da pseudoconcreticidade, conforme sugere Kosik (1976), revelar a "outra face" da responsabilidade social corporativa , pois "é preciso que todos compreendam o que o capitalismo realmente é, e porque sua aparente necessidade e inevitabilidade são, de fato, a pele de cordeiro para ocultar o puro interesse próprio de uma escassa minoria." (SWEEZY, 1977, p. 12).

\section{REFERÊNCIAS BIBLIOGRÁFICAS}

ANTUNES, Ricardo. Os sentidos do trabalho: ensaio sobre a afirmação e a negação do trabalho. São Paulo: Boitempo, 2002, $6^{\text {a }}$ edição. 


\section{FÓRUM ESTUDOS CRÍTICOS EM ADMINISTRAÇÃO-RESPONSABILIDADE SOCIAL CORPORATIVA: POR UMẢ BOA CAUSA? \\ Gianna Maria de Paula Soares}

ASHLEY, Patrícia; Macedo-Soares, T. Diana. In: ENANPAD, 26., 2001, Campinas. Relação de trabalhos.Campinas: ENANPAD, 2001. 1 CD-ROM.

BRAVERMAN, Harry. Trabalho e capital monopolista. Rio de Janeiro: Zahar, 1977.

CHAUÍ, M. S. Público, privado, despotismo. In: NOVAES, Adauto. (Org.). Ética. São Paulo: Schwarcz, 1992, pp. 345-390.

CHAUI, Marilena. Ética e democracia. São Paulo. snb. 1994

CHESNAIS, François. A Mundialização do capital São Paulo: Xamã, 1996.

CODO, Wanderley. O Indivíduo e as Instituições, In: Lane. S.; Codo, W.. (Org) Psicologa Social: o homem em movimento. Brasília: Brasiliense, 1989. p.136-151.

CODO, Wanderley et al. Indivíduo, trabalho e sofrimento. Petrópolis: Vozes, 1994. $2^{\text {a }}$ edição.

CORRÊA, F. T. B. S.; MEDEIROS, J. R. Responsabilidade social corporativa para quem? Disponível em: <http://www.ethos.org.br/docs/comunidade_academica/premio_ethos_valor>Acesso em 27 jun.2003.

DEJOURS, Christophe. A banalização da injustiça social.. Rio de Janeiro: Editora FGV, 2001. $3^{\text {a }}$ edição.

ENRIQUEZ, Eugène. Imaginário social, recalcamento e repressão nas organizações. Revista Tempo Brasileiro, v. 36/37, jan./jun. 1974, p. 53-97.

Prefácio, in Davel, E. e Vasconcellos, J.G. (Org.) "Recursos" Humanos e Subjetividade. Petrópolis. Vozes, 1995. 2a. Edição.

A organização em análise. Vozes, Petrópolis. 1997 (a).

Os desafios éticos nas organizações modernas. Revista de Administração de Empresas, São Paulo, v.37, n..2, p. 6-17, Abr./Jan. 1997.

Interioridade e Organizações. In: DAVEL, E.; VERGARA, S.C. (Org.). Gestão com pessoas e subjetividade. São Paulo: Atlas, 2001, p. 173-187.

FABIÃO, M. F. O Negócio da Ética: um estudo sobre o Terceiro Setor Empresarial. Disponível em: <http://www.ethos.org.br/docs/comunidade_academica/premio_ethos_valor> Acesso em 27.jun. 2003.

FARIA, José Henrique. Tecnologia e processo de trabalho. Curitiba: Editora da UFPR, 1997. 2a edição.

Ética, moral e democracia: os paradoxos da práxis orga nizacional. In: ENEO, 1., 2000, Curitiba. Relação de trabalhos. Curitiba: 2000. 1 CD-ROM. 


\section{FÓRUM ESTUDOS CRÍTICOS EM ADMINISTRAÇÃO- RESPONSABILIDADE SOCIAL CORPORATIVA: POR UMA BOA CAUSA? \\ Gianna Maria de Paula Soares}

Economia Política do Poder: os fundamentos da teoria crítica nos estudos organizacionais. Curitiba, 2002. Texto para discussão, CEPPAD, UFPR, 2002.

FARIA, J. H. e MENEGHETTI F.K. Discursos Organizacionais. In: ENANPAD, 26., 2001, Campinas. Relação de trabalhos.Campinas: 2001 (a). 1 CD-ROM.

Ética e Genética: uma Reflexão sobre a Práxis Organizacional. . In: ENANPAD, 26., 2001, Campinas. Relação de tra balhos.Campinas: ENANPAD, 2001 (b). 1 CD-ROM.

Seqüestro da Subjetividade e as Novas Formas de Controle Psicológico no Trabalho: uma Abordagem Crítica ao Modelo Toyotista de Produção. In: ENANPAD, 26., 2001, Campinas. Relaçãa de trabalhos.Campinas: ENANPAD, 2001 (c). 1 CD-ROM.

. A Instituição da violência nas relações de trabalho. In: ENANPAD, 27., 2002, Salvador. Relação de trabalhos. Salvador: ENANPAD, 2002. 1 CD-ROM.

FREITAS, M. E de. A questão do imaginário e a fronteira entre cultura organizacional e a psicanálise. In: MOTTA, F. C. P.; FREITAS, M. E. de. Vida psíquica e organização. São Paulo: Editora FGV, 2000, p. $41-73$.

GARAY, Angela Beatriz Scheffer. Voluntariado Empresarial: Modismo ou Elemento Estratégico? In: ENANPAD, 26., 2001, Campinas. Relação de trabalhos.Campinas: ENANPAD, 2001. 1 CD-ROM.

INSTITUTO ETHOS. Disponível em < http://www.ethos.org.br>. Acesso em set.2002.

KOSIK, Karel. Dialética do Concreto. São Paulo: Paz e Terra, 1976.

KRAHL, Mara Flora Lottici. O homem e a natureza. Disponível em <http://www.programapantanal.org.br>.. Acesso em: 10 set.2002.

LEAL, A. P.; SCHIMITT E.C. Recursos Humanos e Prática Ideológica: estudo de caso numa organização multinacional. In: ENANPAD, 27., 2002, Salvador. Relação de Trabalhos. Salvador: ENANPAD, 2002. 1 CD-ROM.

LÉVY, A. Ciências Clínicas e Organizações Sociais. Autêntica: Belo Horizonte, 2001.

MARX, Karl. O Capital: crítica de economia política. São Paulo: Nova Cultural, 1985. volume 1, livro 1.

MÉSZÁROS, István. Para Além do Capital: rumo a uma teoria da transição. São Paulo: Boitempo, 2002.

O Século XXI : Socialismo ou barbárie? São Paulo: Boitempo, 2003.

PAGÈS, M. et al. O poder das organizações. São Paulo: Atlas, 1987. 


\section{FÓRUM ESTUDOS CRÍTICOS EM ADMINISTRAÇÃO-RESPONSABILIDADE SOCIAL CORPORATIVA: POR UMA BOA CAUSA? \\ Gianna Maria de Paula Soares}

PAULA, A. S. A.; PINTO, J. A. R.; PAIVA, K. C. M. Responsabilidade Social e Ética: Avaliando exemplos e redefinindo resultados organizacionais. In: V Congresso De Ciências Humanas, Letras e Artes, 2001, Ouro preto. Anais eletrônicos... Disponível em: <http://www.ufop.br/ichs/conifes/anais/OGT/ogt0802.htm> Acesso em: 23 jun. 2003.

SROUR, Robert Henry. Poder, cultura e ética nas organizações. Rio de Janeiro: Campus, 1998.

STAHEL, Andri Werner. Capitalismo e entropia: os aspectos ideológicos de uma contradição e a busca de alternativas sustentáveis. In: Cavalcanti, Clóvis. Desenvolvimento e natureza: estudos para uma sociedade sustentável. São Paulo: Cortez, 2001. $3^{\text {a }}$ edição.

SWEEZY, Paul. Prefácio In: BRAVERMAN, Harry. Trabalho e capital monopolista. Rio de Janeiro: Zahar, 1977.

\section{NOTAS}

${ }^{1}$ Toma-se emprestada a expressão usada por Davel; Vasconcellos no título de sua obra: "Recursos" humanos e subjetividade, $2^{\mathrm{a}}$. Ed. Petrópolis. Vozes, 1995.

2 Adota-se, neste trabalho, a distinção conceitual entre capital e capitalismo proposta por Mészáros (2002), segundo a qual o capital é anterior ao capitalismo e, portanto, pode continuar a existir após o capitalismo, visto que esse é uma das formas possíveis de realização do capital. Essa identificação conceitual, entre capital e capitalismo, fez com que as experiências, como a do socialismo real, a que Mészáros (2002) chama de "sistema de capital pós-capitalista", que teve vigência na URSS e nos demais países do Leste europeu no século passado, se mostrassem incapacitadas para superar o sistema de metabolismo social do capital, que se caracteriza pela divisão hierárquica do trabalho e que subordina suas funções vitais ao capital (ANTUNES, 2002);

${ }^{3}$ Informação disponível em: < http://www.ethos.org.br>, consultado em set.2002.

\section{Artigo recebido em 08.112002. Aprovado em28.11.2004.}

\section{Gianna Maria de Paula Soares}

Mestranda em Administração pelo CEPPAD/UFPR.

Interesses de pesquisa: controle social e relações de poder nas organizações; relações de trabalho; paradoxos e contradições nas organizações.

E-mail: giannasoares@yahoo.com.br

Endereço: Rua, Emílio Cornelsen, 198, apto. 34, Ahu, Curitiba - PR, 80540-220. 